\title{
The long-term physical, emotional and psychosexual outcomes related to anal incontinence after severe perineal trauma at childbirth
}

\author{
Angeliki Antonakou ${ }^{1}$
}

Obstetric anal sphincter injuries (OASIS), or third-degree and fourth-degree perineal tears, represent a serious complication at childbirth. The rate of OASIS for primiparous women in the United Kingdom has been reported to have increased from 1.8 to $5.9 \%$ over a twelveyear period ${ }^{1}$. In women who suffered OASIS at first birth, the incidence of a repeat OASIS has been shown to be $8.4 \%$ in hospital-based studies ${ }^{2}$ and $7.2 \%$ in population-based studies ${ }^{3}$ in the United Kingdom. In other countries, the rate of repeat OASIS in hospital-based and population-based studies has been reported to range widely from 2.0 to $7.2 \%{ }^{4,5}$ and from 5.6 to $7.1 \%$, respectively.

Even though there are well defined risk factors for the occurrence of OASIS, such as nulliparity and instrument assistance at birth, the combination of these risk factors in different scoring systems does not allow the accurate prediction of OASIS ${ }^{8}$. Also, there have been only few interventions described that might reduce the risk of OASIS, such as 'hands-on' perineal protection at crowning-11, the use of warm compressions during the second stage of labour and perineal massage during pregnancy ${ }^{12}$.

Using a $5 \%$ average rate of OASIS means that $1 / 20$ first time mothers will suffer severe trauma of their perineum at vaginal birth that cannot be predicted, while there are few available interventions, of yet unclear benefit, to reduce its occurrence at childbirth. Furthermore, the associated morbidity is significant to these women as OASIS is a prominent risk factor for the development of anal incontinence $(\mathrm{Al})^{13}$, which is defined as the involuntary leakage of flatus or/and faeces ${ }^{14}$. Women who have sustained OASIS at birth have a two-fold to three-fold greater risk of developing subsequent $\mathrm{Al}^{13}$, with rates of Al ranging between 7 to $61 \%{ }^{15}$. It has also been reported that 20 to $40 \%$ of women still described symptoms of $\mathrm{Al}$ at twelve months after birth ${ }^{16}$, with significantly increased risks of $\mathrm{Al}$ even after 15 years from childbirth ${ }^{17}$. In the case of long-term $\mathrm{Al}$, there are additional factors that have been reported to aggravate the severity of bowel symptoms, such as age and menopause ${ }^{17}$.

Women who have sustained OASIS at first birth and have a subsequent second pregnancy are exposed to the risk of a repeat OASIS that has been well quantified in the literature ${ }^{2,3}$, and to the potential risk of developing Al that is still to be determined with ongoing research ${ }^{18}$. Even if a repeat OASIS does not occur in the second childbirth, symptoms of Al might still present as a consequence of cumulative pudendal neuropathy, prolonged second labour or even an instrumental delivery at second birth ${ }^{18}$. On the other hand, there are recent reports that the risk of developing long term Al is not associated with the second delivery but only with the severity of OASIS at first childbirth ${ }^{19}$. Moreover, an elective cesarean delivery at second pregnancy has been quoted not to be protective of Al even in cases of a fourthdegree perineal tear at first birth ${ }^{19}$.

Most studies in the literature have focused on the general impact of Al on the quality of life, with only few studies focusing on the specific emotional and psychological consequences of Al following OASIS at childbirth. Women suffering with Al who sustained OASIS at birth have higher rates of negative body image, sexual dysfunction and increased levels of anxiety and depression ${ }^{20-22}$. It has been described that these women feel embarrassed and ashamed $^{21}$. Women with AI resulting from OASIS have been described recently to have a

\section{AFFILIATION \\ 1 Midwifery Department, Alexander Technological Educational Institute of Thessaloniki, Greece \\ CORRESPONDENGE TO \\ Angeliki Antonakou. Midwifery Department, Alexander Technological Educational Institute of Thessaloniki, Sindos, 57400 Thessaloniki, Greece}

\section{KEYWORDS}

perineum, trauma, childbirth, anal incontinence, psychosexual morbidity, anxiety

\section{$\nabla$}

Received: 22 April 2018

Revised: 1 June 2018

Accepted: 17 July 2018 
previously unrecognised syndrome called the 'OASIS syndrome' that represents a complex of particular social, emotional and psychosexual suffering ${ }^{22}$. Women with this 'OASIS syndrome' suffer the physical symptoms of Al in silence and feel too embarrassed to seek help as they feel stigmatised. They feel unclean and develop rituals of repetitive cleaning on a daily basis; they suffer guilt, fear, social isolation and loss of confidence. They suffer significant sexual morbidity and marital distress, with $1 / 8$ never resuming intercourse and $1 / 12$ experiencing a failed partnership or marriage ${ }^{22}$. Some of these women feel that even their maternal role is compromised by their condition ${ }^{22}$.

Despite the known association between OASIS and Al after birth, there are reports that only 1/5 with OASIS are being asked by their health care practitioners if they have bowel symptoms after childbirth ${ }^{23}$. This finding reflects the fact that health professionals either misunderstand or lack the interest and knowledge of how to investigate and support these women ${ }^{22}$. Since the emotional, social and psychosexual adverse effects of Al after OASIS represent a recognisable syndrome, there should be greater awareness by midwives to detect it early and to promptly refer these women in the postpartum period for further assessment, support and management ${ }^{22,24,25}$. In the United Kingdom there is currently no nationally agreed care pathway for women with Al following OASIS or any appropriate questionnaire of bowel symptoms that could assist midwives in their role of identifying these women ${ }^{22}$.

At the moment, midwives should inform women that the bowel function in the postnatal period is an area that warrants serious attention and that being anally incontinent is not a normal consequence of having a baby, and therefore they should be empowered to seek help and support. This would be in line with the role of healthcare practitioners in improving patient safety in health systems worldwide as advocated in the World Health Organization fundamental principles ${ }^{26}$. Moreover, in the ongoing research on patient safety in the context of maternity care with regard to the occurrence of anorectal symptoms after childbirth, the key concepts that need to be addressed involve the potential lack of communication between health practitioners and these women, as well as the management of this stressful and debilitating harmful event once it has occurred $^{27}$.

\section{REFERENGES}

1. Gurol-Urganci I, Cromwell DA, Edozien LC,et al. Third- and fourth-degree perineal tears among primiparous women in England between 2000 and 2012: time trends and risk factors. BJOG 2013;120(12):1516-25. doi: 10.1111/1471-0528.12363.

2. Antonakou A, Papoutsis D, Henderson K, Qadri Z, Tapp A. The incidence of and risk factors for a repeat obstetric anal sphincter injury (OASIS) in the vaginal birth subsequent to a first episode of OASIS: a hospital-based cohort study. Arch Gynecol Obstet 2017;295(5):1201-1209. doi: 10.1007/s00404-017-4352-6.

3. Edozien LC, Gurol-Urganci I, Cromwell DA, Adams EJ, Richmond DH, Mahmood TA, van der Meulen JH. Impact of third- and fourth-degreeperinealtearsatfirstbirthonsubsequentpregnancyoutcomes:acohortstudy.BJ0G2014;121(13):1695-703. doi: 10.1111/1471-0528.12886.

4. Yogev Y, Hiersch L, Maresky L, Wasserberg N, Wiznitzer A, Melamed N. Third and fourth degree perineal tears--the risk of recurrence in subsequent pregnancy. J Matern Fetal Neonatal Med 2014;27:177-81 doi: 10.3109/14767058.2013.806902.

5. Scheer I, Thakar R, Sultan AH. Mode of delivery after previous obstetric anal sphincter injuries (OASIS)--a reappraisal? Int Urogynecol J Pelvic Floor Dysfunct 2009;20(9):1095-101. doi: 10.1007/s00192-009-0908-8.

6. Baghestan E, Irgens LM, Børdahl PE, Rasmussen S. Risk of recurrence and subsequent delivery after obstetric anal sphincter injuries. BJOG 2012;119(1):62-9. doi: 10.1111/j.1471-0528.2011.03150.x.

7. Jangö H, Langhoff-Roos J, Rosthøj S, Sakse A. Risk factors of recurrent anal sphincter ruptures: a population-based cohort study. BJOG 2012;119(13):1640-7. doi: 10.1111/j.1471-0528.2012.03486.x.

8. RCOG green-top guideline No. 29. The management of third and fourth degree perineal tears. London: RCOG Press; 2015.

9. Hals E, Oian P, Pirhonen T, et al. A multicenter interventional program to reduce the incidence of anal sphincter tears. Obstet Gynecol 2010;116(4):901-8. doi: 10.1097/AOG.Ob013e3181eda77a.

10. Laine K, Skjeldestad FE, Sandvik L, Staff AC. Incidence of obstetric anal sphincter injuries after training to protect the perineum: cohort study. BMJ Open 2012;2(5): e001649. doi: 10.1136/bmjopen-2012-001649.

11. The OASI care Bundle Project: https://www.rcog.org.uk/OASICareBundle. Accessed April 2018.

12. Aasheim V, Nilsen ABV, Reinar LM, Lukasse M. Perineal techniques during the second stage of labour for reducing perineal trauma. Cochrane Database Syst Rev 2017;6:CD006672. doi: 10.1002/14651858.CD006672.pub3.

13. LaCross A, Groff M, Smaldone A. Obstetric anal sphincter injury and anal incontinence following vaginal birth: a systematic review and meta-analysis. J Midwifery Womens Health 2015;60(1):37-47. doi: 10.1111/jmwh.12283.

14. Haylen BT, de Ridder D, Freeman RM, et al. An International Urogynecological Association (IUGA)/International Continence Society (ICS) joint report on the terminology for female pelvic floor dysfunction. Int Urogynecol J 2010;21(1):5-26. doi: 10.1007/s00192-009-0976-9. 
15. Cornelisse S, Arendsen LP, van Kuijk SM, Kluivers KB, van Dillen J, Weemhoff M. Obstetric anal sphincter injury: a follow-up questionnaire study on longer-term outcomes. Int Urogynecol J 2016;27(10):1591-6. doi: 10.1007/s00192-016-3017-5.

16. Andrews V, Shelmeridine S, Sultan AH, Thakar R. Anal and urinary incontinence 4 years after a vaginal delivery. Int Urogynecol J 2013;24(1):55-60. doi: 10.1007/s00192-012-1835-7.

17. Halle TK, Salvesen KÅ, Volløyhaug I. Obstetric anal sphincter injury and incontinence 15-23 years after vaginal delivery. Acta Obstet Gynecol Scand 2016;95:941-7. doi: 10.1111/aogs.12898.

18. Webb SS, Yates D, Manresa M, Parsons M, MacArthur C, Ismail KM. Impact of subsequent birth and delivery mode for women with previous OASIS: systematic review and meta-analysis. Int Urogynecol J 2017;28(4):507-514. doi:10.1007/ s00192-016-3226-y.

19. Jangö H, Langhoff-Roos J, Rosthøj S, Saske A. Long-term anal incontinence after obstetric anal sphincter injury-does grade of tear matter? Am J Obstet Gynecol 2018;218:232.e1-232.e10. doi: 10.1016/j.ajog.2017.11.569.

20. Tucker J, Clifton V, Wilson A. Teetering near the edge; women's experiences of anal incontinence following obstetric anal sphincter injury: an interpretive phenomenological research study. Aust N Z J Obstet Gynaecol 2014;54(4):377-81. doi: 10.1111/ajo.12230.

21. Williams A, Lavender T, Richmond DH, Tincello DG. Women's experiences after a third-degree obstetric anal sphincter tear: a qualitative study. Birth 2005;32(2):129-36. doi: 10.1111/j.0730-7659.2005.00356.x.

22. Keighley MR, Perston Y, Bradshaw E, Hayes J, Keighley DM, Webb S. The social, psychological, emotional morbidity and adjustment techniques for women with anal incontinence following Obstetric Anal Sphincter Injury: use of a word picture to identify a hidden syndrome. BMC Pregnancy Childbirth 2016;16(1):275. doi:10.1186/s12884-016-1065-y.

23. Brown S, Gartland D, Perlen S, McDonald E, MacArthur C. Consultation about urinary and faecal incontinence in the year after childbirth: a cohort study BJOG 2015;122(7):954-62. doi: 10.1111/1471-0528.12963.

24. Salmon D. A feminist analysis of women's experiences of perineal trauma in the immediate post-delivery period. Midwifery 1999;15(4):247-56. doi: 10.1054/midw.1999.0182.

25. Rasmussen JL, Ringsberg KC. Being involved in an everlasting fight--a life with postnatal faecal incontinence. A qualitative study. Scand J Caring Sci 2010;24(1):108-15. doi: 10.1111/j.1471-6712.2009.00693.x.

26. World Health Organization. Regional Office for the Eastern Mediterranean Patient safety tool kit/World Health Organization. Regional Office for the Eastern Mediterranean. 2015.

27. Runciman W, Hibbert P, Thomson R, Van Der Schaaf T, Sherman H, Lewalle P. Towards an International Classification for Patient Safety: key concepts and terms. Int J Qual Health Care 2009;21:18-26. doi: 10.1093/intqhc/mzn057. 